\title{
An Experimental Study on the Performance of Calcium Carbonate Extracted from Eggshells as Weighting Agent in Drilling Fluid
}

\author{
Raheel Iqbal \\ Institute of Petroleum \& Natural Gas \\ Engineering, Mehran University of \\ Engineering \& Technology, \\ Jamshoro, Pakistan \\ 15PG46@students.muet.edu.pk
}

Faisal Abro

Institute of Petroleum \& Natural Gas

Engineering, Mehran University of

Engineering \& Technology,

Jamshoro, Pakistan

faisal.abro@hotmail.com

\author{
Muhammad Zubair \\ Institute of Petroleum \& Natural Gas \\ Engineering, Mehran University of \\ Engineering \& Technology, \\ Jamshoro, Pakistan \\ 13pet04@students.muet.edu.pk
}

Muhammad Ali

Institute of Petroleum \& Natural Gas

Engineering, Mehran University of

Engineering \& Technology,

Jamshoro, Pakistan

muhamadali5014@gmail.com

\author{
Fawad Pirzada \\ Institute of Petroleum \& Natural Gas \\ Engineering, Mehran University of \\ Engineering \& Technology, \\ Jamshoro, Pakistan \\ fawadpirzada8@gmail.com \\ Avinash Valasai \\ Department of Mining Engineering, \\ Mehran University Of Engineering \& \\ Technology, \\ Jamshoro, Pakistan \\ amvalasai@gmail.com
}

\begin{abstract}
Drilling mud density is an important factor in drilling operations. The cost of the drilling mud used for oil and gas well drilling can be $10 \%-15 \%$ of the total drilling cost, and the deeper the well, the more the needed drilling mud. This research aims to prepare a mud that provides performance similar to the conventional mud and to lower down the dependency of primordial $\mathrm{CaCO}_{3}$ technology by exploring it from trash/polluted and naturally occurring materials. For that purpose, a mud was prepared by replacing primordial $\mathrm{CaCO}_{3}$ with $\mathrm{CaCO}_{3}$ derived from eggshells, as eggshells contain $\mathrm{CaCO}_{3}$ in high amounts ranging from $70 \%$ to $95 \%$. The success of this project will provide an affordable solution and an alternative way to explore new methodologies of obtaining $\mathrm{CaCO}_{3}$. The obtained results of this research are quite satisfactory. $\mathrm{CaCO}_{3}$ obtained from eggshells is used in high amounts, $275-410 \mathrm{~g}$ to achieve density ranges from 9.5 to 11.0 pounds per gallon whereas, the needed quantity of pure $\mathrm{CaCO}_{3}$ is $150 \mathrm{~g}$ to obtain density of 10.5 pounds per gallon. Apart from this, it is also observed that eggshell based $\mathrm{CaCO}_{3}$ samples are more efficient in rheological properties compared to the market samples of $\mathrm{CaCO}_{3}$. The $\mathrm{pH}$ of pure $\mathrm{CaCO}_{3}$ sample of 10.5 pounds per gallon density is almost the same with the sample of eggshell $\mathrm{CaCO}_{3}$ of 10.5 pounds per gallon density.
\end{abstract}

Keywords-drilling fluid; weighting agent; mud balance; calcium carbonate; rheological properties

\section{INTRODUCTION}

Drilling fluid has obligatory properties like carrying out rock cutting towards the surface, cleaning and cooling the pit, decreasing resistive forces, stabilizing wellbore, and preventing fluids to flow from pores into the borehole. Various methods for designing suitable drilling muds are developed for avoiding problems encountered during drilling. The drilling mud should be user friendly, cost effective and economically viable. Therefore drilling muds are basically formulated to decrease the effect of damage and to ensure the possibility and economically viability of rotary drilling in hydrocarbon containing formations. The filter cakes which are formed after the intrusion of drilling mud in the pore space of pay zone are compressible and contain varying porosity and permeability characteristics, with low void spaces at the filter channel surface and maximum void spaces on cake surface. In order to reduce filtrate invasion, fluid loss additives such as organic polymers which prohibit water invasion are used. During the formulation of the mud, the microscopic structure and composition of the filter cake related to it and the information of the characteristics of filtration are of main importance [1]. During drilling and completion varying drilling muds in the borehole are used. The most significant factor is the physical and chemical compatibility of the mud with the reservoir rock. By formation damage these muds can reduce the productivity of the well by invasion. Consequently additives are used i.e. $\mathrm{CaCO}_{3}$, which can reduce the chance of these damages in the formations by forming a filter cake of low permeability (optimum thickness) that reduces further invasion of solids and filtrate the pore spaces of rock. After drilling these cakes are washed by for maximizing the flow in the wellbore. Fluid loss and viscosity of mud are important factors which must be investigated throughout the drilling of a well [2]. For that reason, mud is treated with several types of additives i.e. different polymers and chemicals, to achieve requirements important for the particular well such as rheology, control of 
fluid loss, weight of mud etc. Starch and calcite are the most important materials used to control fluid loss and to increase the weight of mud by forming mud cake respectively [3].

\section{EXPERIMENTAL WORK}

\section{A. $\mathrm{CaCO}_{3}$ Analysis in Eggshells by Titration Technique}

Calcite is a major component of eggshells ranging from $70 \%$ to $95 \%$. The technique of titration named as back titration is used for the reaction of acids with calcium present in the blended powder of eggshells. Calcium dissolves in acids rather than pure water:

$$
\mathrm{CaCO}_{3(\mathrm{~s})}+2 \mathrm{HCl}_{(\mathrm{aq})} \rightarrow \mathrm{CaCl}_{2(\mathrm{aq})}+\mathrm{H}_{2} \mathrm{O}_{(\mathrm{l})}+\mathrm{CO}_{2(\mathrm{~g})}
$$

This reaction is slow mostly when it reaches completion hence this technique cannot be directly used. Sufficient amount of acid must be added to dissolve all the calcium carbonate. Then, sodium hydroxide will be added that will react with the remaining $\mathrm{HCl}$. The unreacted amount is calculated by determining the difference between the amount of $\mathrm{HCl}$ that was added initially and the amount of $\mathrm{HCl}$ that remained after the titration. The $\mathrm{CaCO}_{3}$ amount present in the sample is calculated as discussed. Given equation is used to determine the amount of $\mathrm{CaCO}_{3}$ in the sample:

$$
\mathrm{NaOH}_{(\mathrm{aq})}+\mathrm{HCl}_{(\mathrm{aq})} \rightarrow \mathrm{H}_{2} \mathrm{O}_{(\mathrm{l})}+\mathrm{NaCl}_{(\mathrm{aq})}
$$

\section{B. Drilling Fluid Preparation and Properties}

A few additives along with Barite $\mathrm{BaSO}_{4}$, Calcite $\mathrm{CaCO}_{3}$ are commonly used in water-based drilling mud. The three main factors which affect drilling fluid performance are density, viscosity and $\mathrm{pH}$. Fluid samples preparation at laboratory scale is obtained by adding chemicals taken in grams into $350 \mathrm{ml}$ barrels (standard laboratory barrel). This research involves the preparation of five water-based drilling fluid samples which contain bentonite as a filtration controller and viscosifier, caustic soda for $\mathrm{pH}$ control, and starch for filtration control. Along with them, soda ash and Xanthan gum are also used as hardness and rheology control materials respectively. The composition of all these additives is constant for all prepared samples except Calcite. The most important part of these samples is the concentration of $\mathrm{CaCO}_{3}$ as a weighting agent. It is used to increase densities of samples from 9.0 to 11 pounds per gallon (ppg). The required amount of $\mathrm{CaCO}_{3}$ as a weighting agent is determined by:

Weighting Agent $($ Sacks $/ 100$ Barrels $)=\frac{945(W 2-W 1)}{22.5-W 2}$

And the formula to determine the required amount of Barite as a weighting agent can be written as:

$$
\text { Weighting Agent (Sacks/100 Barrels })=\frac{1470(W 2-W 1)}{35-W 2}
$$

where, $W 1$ is indicating the initial weight of mud (ppg) and $W 2$ is indicating the required weight of mud (ppg).

\section{Density of Mud}

Mud density is the main parameter to consider during study as it directly affects the formation of filter cake. The most common additive to increase the mud weight in production zones is mostly calcite $\left(\mathrm{CaCO}_{3}\right)$ which is widely used during drilling of zone of interest. Five drilling mud samples by formulating both calcites (pure calcium carbonate, eggshell calcium carbonate) are prepared in this study to achieve densities ranging from 9.5 to $11.0 \mathrm{ppg}$. The amount used for the formulation of pure calcite base sample is $150 \mathrm{~g}$ as shown in Table I, and the amount for the formulation of eggshells based samples ranges from $275 \mathrm{~g}$ to $410 \mathrm{~g}$ as shown in Figure 1 to achieve mud density from 9.5 to $11.0 \mathrm{ppg}$.

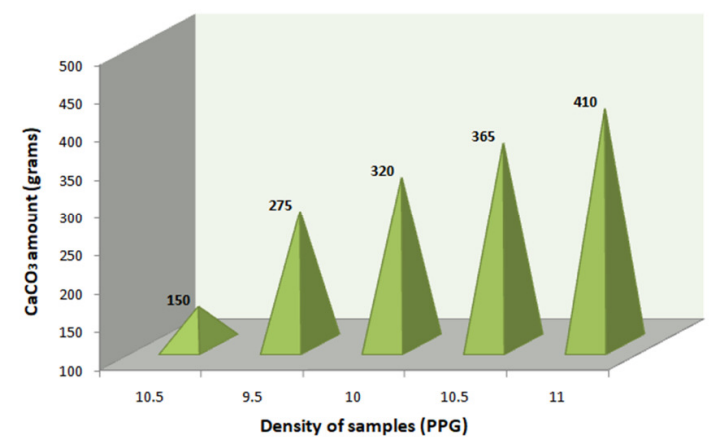

Fig. 1. Amount of calcium carbonate vs densities

\section{Drilling fluid rheological properties}

Rheological properties are categorized in gel strength, yield point and apparent viscosity. Rheology is the basis of all investigations ranging from hydraulics of wellbore to the evaluation of mud system functionality. Mud rheological properties are continuously tested throughout the drilling operation. Mud rheological properties are very critical to maintain control while tackling the wellbore problems, because inappropriate rheological properties may result in loss of time and money. Besides rheological properties, filtration, $\mathrm{pH}$, chemical analysis (alkalinity and lime content, chloride content, calcium content, etc.), and resistivity are also tested throughout the drilling. In the laboratory (as in the drilling site), a rotational viscometer is frequently used to measure the rheological properties of mud. Readings are taken on 600, 300, 200, 100, 60, 30 and 6rpm (rotations per minute). Later these readings are plotted on a chart of shear stress and shear rate which are used to determine viscosity and appropriate viscosity model. Rotational viscometer also provides the information about other rheological properties, including effective viscosities $(\mu a, \mu p$, and $\mu e)$, gel strength $(G e l)$ and yield point $(Y p)$ as shown in Table II.

Given equations are utilized for these purposes:

$$
\begin{aligned}
& \text { Apparent Viscosity } \mu a,(\mathrm{cp})=\frac{\varnothing 600}{2} \\
& \text { Plastic Viscosity } \mu p,(\mathrm{cp})=\varnothing 600-\emptyset 300 \\
& \text { Effective Viscosity } \mu e,(\mathrm{cp})=\frac{300 \times \emptyset}{\omega} \\
& \text { Yield Point } Y p,\left(\mathrm{lb} / 100 \mathrm{ft}^{2}\right)=\varnothing 300-\mu p \\
& \text { Shear Stress } \tau,\left(\mathrm{lb} / 100 \mathrm{ft}^{2}\right)=1.065 * \varnothing \\
& \text { Shear Rate } \gamma, \mathrm{sec}^{-1}=1.7023 * \omega
\end{aligned}
$$


where, $\varnothing$ indicates the reading of dial, $\mathrm{lb} / 100 \mathrm{ft}^{2}$ and $\omega$ indicates rotation of rotor speed (rpm). Bingham plastic model is a basic two-parameter model used in drilling industry widely to identify the properties related to flow for the different mud types. It is known as the most common fluid model to estimate non-Newtonian fluids' rheology. Shear stress is a straight line function of shear rate which is the basic supposition of this model. Yield point is also named as threshold stress, it is the point where shear rate is zero. By the reduction in colloidal solids, the optimum plastic viscosity (PV) is achieved.

TABLE I. DRILLING MUD SAMPLES AND ITS COMPOSITION

\begin{tabular}{|c|c|c|c|c|c|}
\hline Product & \multicolumn{5}{|c|}{ Per lab barrel (350 ml) } \\
\hline Sample number & $\mathbf{1}$ & $\mathbf{2}$ & $\mathbf{3}$ & $\mathbf{4}$ & $\mathbf{5}$ \\
\hline Water (ml) & 325.50 & 325.50 & 325.50 & 325.50 & 325.50 \\
\hline Bentonite (g) & 24.50 & 24.50 & 24.50 & 24.50 & 24.50 \\
\hline Barite & - & - & - & - & - \\
\hline Pure CaCO $\mathbf{C a}_{\mathbf{3}} \mathbf{( g )}$ & 150 & - & - & - & - \\
\hline Eggshell $\mathbf{C a C O}_{\mathbf{3}} \mathbf{( g )}$ & - & 275 & 320 & 365 & 410 \\
\hline Starch (g) & 0.40 & 0.40 & 0.40 & 0.40 & 0.40 \\
\hline Caustic soda (g) & 0.20 & 0.20 & 0.20 & 0.20 & 0.20 \\
\hline Soda ash (g) & 0.25 & 0.25 & 0.25 & 0.25 & 0.25 \\
\hline Xanthanum (g) & 1.00 & 1.00 & 1.00 & 1.00 & 1.00 \\
\hline
\end{tabular}

TABLE II. RHEOLOGICAL PROPERTIES OF MUD SAMPLES

\begin{tabular}{|c|c|c|c|c|c|}
\hline Sample number & 1 & 2 & 3 & 4 & 5 \\
\hline Plastic Viscosity $(c p)$ & 22 & 10.5 & 17.1 & 23 & 32 \\
\hline Apparent Viscosity ( $c p$ ) & 38 & 20.5 & 33 & 39.25 & 50 \\
\hline Yield Point $\left(\mathbf{l b} / \mathbf{1 0 0} \mathrm{ft}^{2}\right)$ & 32 & 20 & 31.8 & 32.5 & 36 \\
\hline $\begin{array}{c}\text { Gel Strength@10 min } \\
\left(\mathbf{l b} / 100 \mathrm{ft}^{2}\right)\end{array}$ & 16.5 & 12.8 & 19.5 & 20 & 20.6 \\
\hline$\theta_{600}$ & 76 & 41 & 66 & 78.5 & 100 \\
\hline$\theta_{300}$ & 54 & 30.5 & 48.9 & 55.5 & 68 \\
\hline$\theta_{200}$ & 45 & 26.5 & 42 & 46 & 56 \\
\hline$\theta_{100}$ & 35 & 21.5 & 33 & 35.5 & 42 \\
\hline$\theta_{60}$ & 29 & 19 & 29 & 31 & 36 \\
\hline$\theta_{30}$ & 19.5 & 17 & 25 & 26 & 29 \\
\hline$\theta_{6}$ & 15 & 13 & 19 & 19.5 & 21 \\
\hline
\end{tabular}

To carry cuttings out of the hole, yield point should be high enough, but not very much because pump pressure would become incompatible with drilling operation. For both low and high shear rates ranges, Bingham plastic model has its own limitations. The physical/solid reason behind this behavior is that the liquid generally contains particles (clay) or large molecules (polymers) which generally have some kind of interaction, while creating a weak solid structure, known as a false body, and at that point a certain amount of stress is required to break it. Under viscous forces the particles tend to move as the structure breaks. The results which are acceptable for a drilling mud diagnosis are produced by Bingham plastic model. But, for hydraulic calculations its accuracy is not very high. A Bingham body doesn't begin to flow until a shearing stress, corresponding to the yield value, is exceeded. The results for the Bingham plastic model are obtained by the graph between shear stress and shear rate in Figure 2, plotted with the use of (6) and (7).

\section{E. Drilling Fluid pH Determination}

It is important to know mud $\mathrm{pH}$ because it affects the solubility of the organic thinners, contaminant removal, corrosion mitigation, and the dispersion of clays present in the mud. pH is mostly used to express drilling fluid's, especially water-based mud, acidity or alkalinity. Generally, its value ranges from 0 to 14 . $\mathrm{pH}$ is expressed by (9):

$$
\mathrm{pH}=-\log [\mathrm{H}]
$$

where, $[\mathrm{H}]$ is the hydrogen ion concentration in mol. $\mathrm{pH}$ value decreases as the acidity of the fluid increases by the addition of more hydrogen atoms. Generally, $\mathrm{pH}$ of the neutral fluid is 7. Values above 7 indicate alkaline $\mathrm{pH}$ below 7 indicate acidic $\mathrm{pH}$.

In drilling mud there are three main chemical components involved which are hydroxyl ions $\left(\mathrm{OH}^{-}\right)$, carbonate ions $\left(\mathrm{CO}_{3}^{-2}\right)$ and alkalinity of drilling mud including $\left(\mathrm{HCO}_{3}{ }^{-}\right)$bicarbonates ions. For better $\mathrm{pH}$ measurement, $\mathrm{pH}$ meter is mostly used rather than the litmus paper, because $\mathrm{pH}$ meter provides quantitative information where litmus paper provides qualitative information about the acidity of the drilling mud.

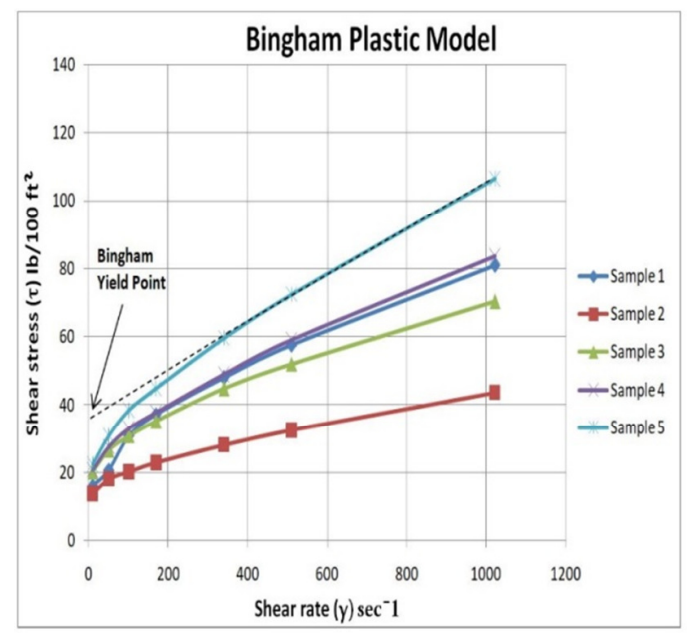

Fig. 2. Bingham plastic model of samples

\section{RESULTS AND DISCUSSION}

\section{A. $\mathrm{CaCO}_{3}$ Determination by Back Titration}

The outcomes from the back titration method for the $\mathrm{CaCO}_{3}$ amount can be determined by washing, boiling, peeling off the membranes, and heating of the eggshells at $120^{\circ} \mathrm{C}$, and the resulting value is showing $74 \%$ presence of $\mathrm{CaCO}_{3}$ in the eggshells blended powder.

\section{B. Characteristics of Drilling Fluids}

The densities of 5drilling fluid samples of both ordinary $\mathrm{CaCO}_{3}$ and eggshell $\mathrm{CaCO}_{3}$, ranging from 9.0 to $11.0 \mathrm{ppg}$ are shown in Figure 1. Table II provides comprehensive information about the rheological properties of the prepared sample. Variations in rheological properties were observed with the increase of amount of $\mathrm{CaCO}_{3}$ of eggshells. Besides this, the purpose of increased density was achieved by increasing the amount of $\mathrm{CaCO}_{3}$ obtained from eggshells. In general, the increment in sample density causes increment in rheological properties' values. Meanwhile, the drilling fluid sample No. 4 (based on 10.5 ppg eggshell $\mathrm{CaCO}_{3}$ ) exhibits 
similar rheological property values with sample No. 1 (based on 10.5 ppg pure $\mathrm{CaCO}_{3}$ ).

\section{Bingham Plastic Model}

It is discussed that non-Newtonian fluids exhibit a relationship between shear rate and shear stress measured for the formulated samples as shown in Figure 2. According to the graphs which are plotted for 5 water-based drilling fluid samples, shear stress increases with increasing amount of eggshell $\mathrm{CaCO}_{3}$, while pure $\mathrm{CaCO}_{3}$ sample No. 1 is showing almost the same trend with the sample No. 4 of eggshell $\mathrm{CaCO}_{3}$. A general trend line is drawn for the Bingham plastic fluid and it is observed that the yield point of $36 \mathrm{Ib} / 100 \mathrm{ft}^{2}$ is obtained for eggshell $\mathrm{CaCO}_{3}$ sample No. 5, and it is also measured by viscometer and discussed in Table II.

\section{D. $p H$ Determination}

The $\mathrm{pH}$ of the prepared sample is determined by using $\mathrm{pH}$ meter and the obtained results are shown in Figure 3. If a comparison is generated between the Calcite based samples of same densities then it is observed that the sample No. 1 of pure $\mathrm{CaCO}_{3}$ has almost the same $\mathrm{pH}$ value with the sample No. 4 of eggshell $\mathrm{CaCO}_{3}$ with 10.5 ppg density, which indicates that there is no impact of the amount of $\mathrm{CaCO}_{3}$ on the $\mathrm{pH}$ of both samples. The required amounts for both samples are varying but as density reached $10.5 \mathrm{ppg}$ for both samples, they show almost the same $\mathrm{pH}$.

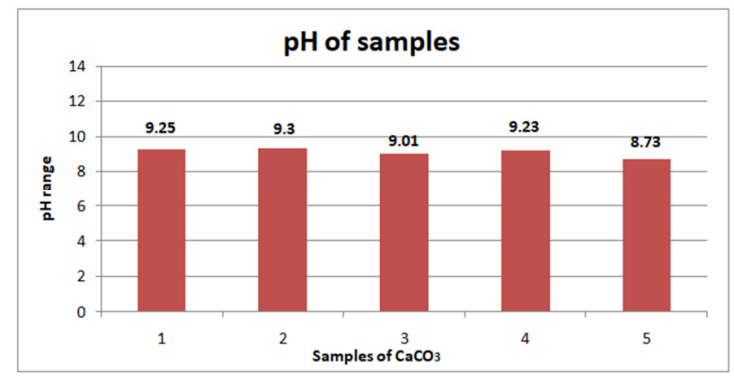

Fig. 3. $\mathrm{pH}$ of samples

\section{CONCLUSION}

On the basis of laboratory measurements analysis and interpretation, the main concluded points are:

- Mud density of $10.5 \mathrm{lb} / \mathrm{gal}$ is optimum for the X well. It was selected among 5 prepared mud densities, considering that it can sustain formation pressure. By using another mud density the formation starts to create fractures in the well.

- $\mathrm{CaCO}_{3}$ obtained from eggshells is used in higher amounts from $275 \mathrm{~g}$ to $410 \mathrm{~g}$ to achieve densities ranging from 9.5 to $11.0 \mathrm{lb} /$ gal. Pure $\mathrm{CaCO}_{3}$ took only $150 \mathrm{~g}$ to obtain density of $10.5 \mathrm{lb} /$ gal. Apart from this, it is also observed that eggshell $\mathrm{CaCO}_{3}$ samples are more efficient in rheological properties than the samples from market $\mathrm{CaCO}_{3}$.

- It is observed that the $\mathrm{pH}$ of pure $\mathrm{CaCO}_{3}$ sample of $10.5 \mathrm{lb} / \mathrm{gal}$ has almost the same value with the sample of eggshell $\mathrm{CaCO}_{3}$ of $10.5 \mathrm{lb} /$ gal density.
- It was observed that the prepared samples of eggshells $\mathrm{CaCO}_{3}$ are producing unpleasant smell after 1-2 days of preparation.

- However, by heating the eggshells at a temperature ranging from $300^{\circ} \mathrm{C}$ to $500^{\circ} \mathrm{C}$, better results for the amount of $\mathrm{CaCO}_{3}$ will be obtained. By doing this the efficiency of the $\mathrm{CaCO}_{3}$ is improved as the acids which are present in the shells are removed and the smell dissipates.

\section{REFERENCES}

[1] K. A. Fattah, A. Lashin, "Investigation of mud density and weighting materials effect on drilling fluid filter cake properties and formation damage", Journal of African Earth Sciences, Vol. 117, pp. 345-357, 2016

[2] S. Gogoi, P. Talukdar, "Use of Calcium Carbonate as bridging and weighting agent in the non damaging drilling fluid for some oilfields of Upper Assam Basin", International Journal of Current Research, Vol. 7, No. 8, pp. 18964-18981, 2015

[3] T. Hudson, M. Coffey, "Fluid loss control through the use of a liquid thickened completion and work over brine", Journal of Petroleum Technology, Vol. 35, No. 10, pp. 1776-1782, 1983

[4] M. Sajjadian, E. E. Motlagh, A. A. Daya, "Laboratory Investigation to Use Lost Circulation Material in Water Base Drilling Fluid as Lost Circulation Pills", International Journal of Mining Science, Vol. 2, No. 1, pp. 33-38, 2016

[5] N. Gaurina-Medimurec, "Laboratory Evaluation of Calcium Carbonate particle size selection for drill-in fluids", Rudarsko-GcolofkoNaftnizbomik, Vol. 14, pp. 47- 53, 2002

[6] A. Odabasi, An Experimental Study of Particle Size and Concentration Effects of Calcium Carbonate on Rheological and Filtration Properties of Drill-in fluids, MSc Thesis, Middle East Technical University, 2015

[7] R. Samavati, N. Abdullah, T. K. Nowtarki, S. A. Hussain, D. R. A. Biak, "Rheological and Fluid Loss Properties of Water Based Drilling Mud Containing HCl-Modified Fufu as a Fluid Loss Control Agent", International Journal of Chemical Engineering and Applications, Vol. 5, No. 6, pp. 446-450, 2014

[8] M. Amani, J. K. Hassiba, "The Effect of Salinity on the Rheological Properties of Water Based Mud under High Pressures and High Temperatures for Drilling Offshore and Deep Wells", SPE Kuwait International Petroleum Conference and Exhibition, Kuwait City, Kuwait, 10-12 December, 2012

[9] P. K. Jha, V. Mahto, V. K. Saxena, "Emulsion Based Drilling Fluids: An Overview", International Journal of Chem Tech Research, Vol. 6, No. 4, pp. 2306-2315, 2014

[10] P. Talalay, Z. Hu, H. Xu, D. Yu, L. Han, J. Han, L. Wang, "Environmental considerations of low-temperature drilling fluids", Annals of Glaciology, Vol. 55, No. 65, pp. 31-40, 2014

[11] P. O. Ogbeide, S. A. Igbinere, "The Effect of Additives on Rheological Properties of Drilling Fluid in Highly Deviated Wells", Futo Journal Series, Vol. 2, No. 2, pp. 68-82, 2016

[12] N. Al-Malki, P. Pourafshary, H. Al-Hadrami, J. Abdo, "Controlling bentonite-based drilling mud properties using sepiolite nanoparticles", Petroleum Exploration and Development, Vol. 3, No. 4, pp. 717-723, 2016

[13] C. Kelessidis, "Drilling fluid challenges for oil-well deep drilling", nternational Multidisciplinary Scientific GeoConference SGEM 2009, Albena, Bulgaria, June 14-19, 2009 